\title{
MJN COLLEGE STUDENTS' STRESSORS AND COPING TECHNIQUES: A PRECURSOR TO GOOD MENTAL HEALTH
}

\author{
Elvie A. Paler*, Mae-Lanie O. Poblete, Minnie B. Mamauag, Gerose Febb C. Alarde, \\ Melissa D. Claret \\ College of Nursing, Mindanao State University - Iligan Institute of Technology, Philippines \\ *Corresponding Author's Email:elvie.paler@g.msuiit.edu.ph
}

\begin{abstract}
No one is exempted from experiencing stress in college. Many mental health issues are emerging among young adults especially during their university years. Being exposed to stressors helps every individual in terms of strengthening their well-being. This research aims to find out about the stressors the college students' experiences and their coping techniques in order to relieve these stress faced by them.A qualitative method was used in gathering and analyzing the data, with five college students taken from the different colleges of Mindanao State University - Iligan Institute of Technology as the respondents. An in-depth interview was conducted with three open-ended questions. There were three themes that emerge. (1) College students worry greatly about their academic life. This includes the intellectual, financial, physical and social stresses that they encounter; (2) College students due to academic pressures suffer from a feeling of anxiousness, frustration, tiredness, they are emotionally drained, resulting in low self-esteem; (3) College students have both positive and negative coping strategies. This coping strategy includes support from significant persons; giving time to be alone to revitalize themselves; finding comfort from God's words. The researchers conclude that college students with good mental health have positive coping techniques.
\end{abstract}

\section{Keywords: College students, Coping techniques, Good mental health, Stressor}

\section{INTRODUCTION}

College students are experiencing immense pressure which are concerned with earning good grades, too many projects, homework and incoming exams, time constraints and maintaining good relationship with teachers. The fact that some students are living away from their parents causes more stress in such cases (Hicks \& Heastie, 2008). Problems on how to manage their allowance is an additional baggage. College students must face the responsibility of balancing academics and social life (Chien, 2015). Aside from all these problems encountered at college, the relationship between family and friends also is a source of stress for them (Gupchup, Borrego \& Konduri, 2004).

There are both positive and negative impacts due to stress depending on the situation that the students are facing. A positive impact happens if a person manages a situation well and there will be a negative impact if the person is unable to control these situations. Students make stress as an excuse to engage in drinking alcohol, smoking, use of illegal drug along with clubbing. As a result car or vehicle accidents occur. They get involved in sexual activities that could cause unexpected pregnancy, abuse, trauma and transmission of HIV. This can trigger a person to engage in suicidal tendencies and they are inclined to perform crimes.

They may find this situation negative thus making the student frustrated, depressed and they are unable to cope-up with the present situation. As result the problem remain unresolved. Others may take this situation positively by taking it as a challenge and working harder. A person can be stressed in different 
ways depending on the reaction of the body in adapting the new condition. It is on how a person deals with problems which will determine if the individual feels stressed or not. There are positive and negative consequences when a student feels stress during their academic life. Learning will be suppressed or inhibited when a person feels stressed, and this is called the unfavorable stress which is associated to the student's performance in his/her academics (Siraj et al., 2014).

Stress has been a topic of extensive researcher for many years. Many studies were able to recognize the different stressors that the college students' experiences. The most important source of stress for students is in their academic life and on how the students respond to those stressors. They also must deal with pressure and conflict from peers. As they are away from home they have high expectation of a college life. Consequently, frustrations and depression gradually set in during the adjustments to this new environment. This may also cause financial problems (Gadzella et al., 2012). This present study aims to explore the stressors and coping techniques among college students with good mental health status in Mindanao State University - Iligan Institute of Technology.

\section{Significance of the study}

This study could help us to guide students in managing stressors well and to be able to choose the right ways of coping.

$>$ This study will help the professors and teachers to be aware of the student's stressors that affect their performance at school. Moreover, their behaviour can also be one of the factors that affect student's stress. Thus, they will be able to enhance techniques in handling stressful situations towards their students.

$>$ The family of every student will be able to understand and be more sensitive to their son/daughters needs and can also change or improve their way of communication at home.

The University administration will be able to understand the e student's ability to deal with stressors and the contributing factors to stress. Thus, they will be able to create programs and provide awareness in dwelling with stressful situations, reducing negative effects and will be able to guide them so that they engage themselves in positive coping techniques.

\section{METHODOLOGY}

This study involved a qualitative type of research method utilizing an in-depth interview exploring the different stressor and coping strategies of college students. Five (5) College Students from Mindanao State University- Iligan Institute of Technology, aged between 18-21 years old with good mental health status were the participants of the study. They were chosen based on the following criteria; having a good academic standing, leaders in their colleges and other organizations, and active in both academics and extracurricular activities.

In conducting the study, the researchers made use of a guided questionnaire with three open-ended questions to elicit information on stressors and coping techniques of the research participants. During the interview, informed consents were drawn from the participants to take into consideration all ethical issues in the conduct of the study. The interview lasted for 45 minutes with audio recording as allowed by the participants.

After the interview, the data were transcribed in verbatim and translated from vernacular to the English language. Then, themes were extracted based on content analysis.

\section{RESULTS AND DISCUSSION}

This section covers the results and discussion of data gathered based on the objectives of the study. The table below shows the demographic profile of the participants. There were three male and two female participants aged 18-21 years old with a grade point average ranging from 1.3 to 2.2. Most of them are living away from home and were given a monthly allowance ranging from 3,000-5,500 pesos. College students have the pressured to perform well in academics and should adjust on the fact that they're living away from home. Moreover, they are socializing to new kind of environment and people. Thus, these stressors experienced by college students results in conflicts, frustration, mental pressures and changes (Hamaideh, 2011). 
Table 1: Demographic Profile of College Students

\begin{tabular}{|l|l|l|l|l|l|}
\hline Participants & Age & Gender & GPA & $\begin{array}{l}\text { Monthly } \\
\text { Allowance }\end{array}$ & Mode of Residence \\
\hline 1 & 20 & Female & 1.8 & 5,000 & Boarding House \\
\hline 2 & 21 & Male & 1.3 & 5,500 & Boarding House \\
\hline 3 & 20 & Female & 1.9 & 4,300 & Boarding House \\
\hline 4 & 19 & Male & 2.2 & 3,500 & Boarding House \\
\hline 5 & 18 & Male & 1.9 & 3,000 & $\begin{array}{l}\text { Lives at Home (within } \\
\text { Iligan City) }\end{array}$ \\
\hline
\end{tabular}

\section{EMERGENT THEME}

From the content analysis, there were three themes that emerged after thorough exploration.

Theme 1: College students worry greatly about their academic life. This includes the intellectual (exams and other academic requirements), financial (allowance and logistical needs) physical (course load and deadlines) and social (teacher, family and personal relationships) stresses they encountered as they study.

The study shows that college students worry about academic exam performance and completion of other academic requirements. As stated by participant 1, "At school, academics, exams and requirements all these stresses me. Examination overload together with other requirements trigger stress in me". There are times that students are loaded with exams plus they must submit other required assignments within deadlines. So, the college students feel the need to manage their time wisely. As stated by participant 5, "For now, what stresses me most is when have to face many exams simultaneous. I feel so stressed this week because we have four exams". The need of adjusting to different kinds of teachers also gives them stress. As stated by participant 2, "Our new teacher is stricter than before and there are many requirements". College students often feel frustrated of the poor outcome they face after putting too much effort. This includes studying endlessly yet getting low scores on exam. As stated by participant 4, "What triggers my stress the most are exams, that even if you try so hard during exams and when results come out our scores for that exam does not match our effort exerted".

One of the respondents mentioned extracurricular activities to balance stressor with academics.

"When I was an officer of our college before, that was so stressful and full of pressure because people have high expectations on you. It's really hard to participate in extracurricular activities and at the same time to study for academics because your schedule will beloaded". (Participant 3 )

Family struggles and sudden death or sickness of a loved-one affect the student a lot especially their motivation to continue studying. They feel depressed when a problem within family arises. They are distracted when they have conflicts with their girlfriend or boyfriend, especially when they just go through break-ups. Two out of five participants referred to family related problems as factor to stress. Participant 5 said, "I no longer have parents, my older brother and his wife supports me. I also have a younger sibling. Sometimes if they have problem we also get involved". In the same manner, participant 2 mentioned, "It was October when my grandfather died, and my father died on December. That was the most painful. I was blanked at that time". The fact that they are living away from home, they feel the need to budget their money independently. As stated by participant 1, "Finances also stresses me since I'm living in a dormitory, so I need to budget my money well".

The result of this study is similar to the result of the studies of Pariat et al., (2014) that revealed that the main source of academic stress among college students is known to arise from family expectations, academic results, exams, teachers, peer pressures, time management and course load. It was emphasized that of all the academic stressors, family expectations and teacher expectations contributed the most towards the stress level of the participants.

Moreover, in a survey conducted by the American College Health Association-National College Health Assessment (2015) found out that among the stressful life events that the students had difficulty to handle included academics (63.1\%), finances (36\%), intimate relationships (33\%), sleep difficulties $(32.7 \%)$, other social relationships $(32.4 \%)$ and family problems $(30.9 \%)$. Indeed, college students are confronted with many academic stressors in life.

Theme 2: College students due to academic pressures felt anxious, frustrated, tired, emotionally drained, sad, and lonely resulting to low self-esteem which often affects their academic performance.

Academic burden is the most vital source of stress and pressure to the college students. Students 
experienced negative manifestations regarding these stressors in the mental, physical, emotional and social aspect. These manifestations test the students on how they would cope and what strategies they would apply to surpass the challenges they experience.

"For example, at school, I get anxious. I always think about my requirements. Anxiety, that's what I mostly feel when I'm stressed". (Participant 1)

A student gets anxious because they keep on thinking about the problem over and over, which makes them stick to the problem, then other complications arise that becomes the actual problem.

"Due to my poor performance I can't focus, and it took me a lot of time to recover. My mind set at that time was that I no longer wanted to continue college". (Participant 2)

When students are stressed, it affects their ability to concentrate. Their performance at school would likely to be affected because stress affects the productivity of the students and their willingness to continue reduces in the long run.

"I want to just sleep always. I can also sense that I'm stressed if I can't take care of myself and always feel haggard". (Participant 3)

Fatigue is also one of the manifestations due to the experience of stress. In such cases energy is being used by just thinking about the issues they are facing that causes weakness and when this happens there will be drainage of energy. So, they will not have enough energy to fulfill their academic demands and they will not take care of themselves. This leads to poor academic performance and self-care deficit. Researchers have proven the relationship between the immune system and stress. It was observed that most people experience high level of stress and displays a poorer health. According to Fishman (2012), biological evidences have proved that there are chemical changes in the human body that negatively affect the immune system because of the activation of stress hormones. The disturbance of hormones results in health problems that compromise the health of an individual.

"If I get stressed, sometimes I don't want to talk to people”.(Participant4)

Mostly when students have a lot of issues they prefer to isolate themselves, away from family and friends. They prefer to be alone to think about the issues. There are times that self-isolation helps the students to clear their mind and might help them think of best solutions for their problems. But doing so on regular basis could threaten their relationships towards those people who are close to them since they might feel left out and could possibly cut ties with them. This in the long run could cause much trouble for the individual.

"I lost my self-esteem and confidence. I feel so down and not comfortable, depressed, and I feel distracted". (Participant 5)

Every student aspires to excel in their studies, to have good grades and receive high honors, but when the outcomes are opposite to their expectation or they are not satisfied enough then they feel down, and their motivation is reduced. They then start questioning about the lapses in their previous performance; stress would then be elevated, and they will not be able to do everything in the right manner.

In previous studies, unsettled loneliness can be a source for depressive episodes which can affect all areas of functioning among students including motivation, concentration, feelings of self-worth and mood (Kim, Kim \& Yang, 2015). In the study of Dy and colleagues (2015) on stressors and stress responses of Filipino college students, results revealed that the most frequent responses shown by the respondents on affective domain were anxiety and fear. The affective domain disturbs a person's motivation level, selfesteem level, and degree of socialization which are usually caused by the individual's environment. The student's anxiety was said to be due to persistent anticipation of uncertain events like exams, passing the subjects, and the like while fear is shown as a frequent response most likely due to difficulty of university life and fear of failure. Thus, negative emotions can be powerful sources of stress which can further aggravate the person's mental state.

Theme 3: College students have both positive and negative coping strategies. This coping includes support from significant persons (friends, family, girlfriend/boyfriend, teachers/mentors); giving time to be alone to revitalize self (stress eating and sleep); finding comfort with God's words and believing that 


\section{all these will come to pass if one just believes and persevere.}

All five participants used the social support strategies such as bonding, talking and sharing problems with friends. Participant 1 stated, "At school I try to socialize with my friends. After school I hang out with them before I come home”. Also, participant 2 mentioned, "I was thankful to one of my classmates, he really helped me a lot. He messaged me every night he was good in comforting me". Participant 3 shared that, "Friends are really a big help because you'll have someone to talk about your stress then for me I really just need someone to talk to about my stress". Moreover, both participants 4 and 5 discussed their experiences of having friends around to share their problems and make them feel better.

Four out of five participants used the religious strategy such as going to church and asking help from God, knowing that God will always be with them. This strengthens their will to continue despite of the unending problems. The four participants said, "I also have spiritual coping mechanism; I go to church every Sunday". (Participant 1)

"Of course, going to church every day is important. I always forget to pray every night, but I make sure that I would be able to go to church once a week". (Participant2)

"If I get stress due to family, I just pray for them". (Participant 3)

"I always pray if problem arises in the family, we should ask God to help because he will help you. What you should do is have trust on your parents, and to the Lord. "(Participant 4)

Students also reduce or control their stress level by effectively managing their time and engaging themselves in different studying strategies (Gadzella et al., 2012). One participant has stated about time management and his strategy of studying. As stated by participant 2, "I have my style, I have my own way of time management. I can manage my time in the sense that I won't be stressed for that day and I get to focus on studying. It's like I have a bracket for studying and a bracket for leisure. I can mix them in one day. I'll study for 1 to 2 hours then watch Harry Potter, then repeat studying and then watch Harry Potter while studying. But I only listen to Harry Potter since I have memorized all of its happenings. I won 't be disturbed by that. I want to listen to something while studying. It could be music or Harry Potter but for me Harry Potter is the best. When it comes to solving I prefer loud music, but when I'm reading I prefer minimal volume of music. That's my way of preparing for examinations".

One participant was able to use the avoidance strategy. It is avoiding and doing other things to divert oneself from problems. College students eat a lot and sleep a lot when they are stressed and they do other things that keep them from thinking about the problem. As stated by participant 3, "If I get stress due to academics, I eat a lot and get a lot of sleep. Then I find diversion, I find videos online then dancing really also relieves stress in me". Focusing on other activities relieve their stress and that's the time they can think well and plan for the problem to be solved. Some have also used the positive appraisal kind of strategy by motivating self and the positive thinking in relieving their stress. As stated by participant 4, "I will rectify those mistakes that affected the exam and will not do it again. I'll strive harder so that it will not go to the point that I'll worry again'. College students motivate themselves at times when they are feeling down and at other times by self-talk.

Coping strategies were often classified into two: problem-focused and emotion-focused strategies. The problem-focused strategies involved behavioural activities such as planning and acting accordingly, while the emotion-focused strategies employed altering expectations and expressing emotion (Silvers, 2006; Brougham et al., 2009). There were participants that used problem-focused and emotion-focused strategies. In times of not knowing what to do regarding academics, college students opt to consult with teachers especially with their advisers. As stated by participant 2 , "I consulted someone and was told to go to our adviser. I went to my adviser and sought for advice." The participant were able to express emotion to their instructors regarding academics. Another participant used the planning and action type of strategy. As stated by participant 3, "If all these stressors occur at the same time, first I sort out things then slowly will take actions 
towards it. I also just stay in my room and plan on how to resolve it". There are times that college students want to handle their problems alone, so they tend to distance themselves from other people. By being alone they can think for solutions, but the respondents have also shared about seeking someone if the problem is too hard to handle by just oneself. Participant 1 said, "I want someone to talk to, but sometimes I also just want to be alone if I can handle it myself". Thus, seeking for a friend or someone that the respondents are comfortable with is a big help in relieving stress because then the nurses will be able to express their feelings and let out the anger and friends could also give advice.

Most participants' coping strategies leaned towards positive ways of dealing with academic stressors. None of them resorted to vices like drugs, smoking, drinking alcoholic beverages and harming oneself. The coping mechanism of each individual varies however; studies suggest some general observations in response to stress among female college students which include isolation (spending idly, excessive amounts of time in their room), analyzing the problem little by little, socializing with friends, talking with family members, encouraging oneself that things will get better and visiting place of worship (Ramya \& Parthasarathy 2009; Mathews,
2017). Meanwhile, for male students it was more of having emotional support from family members and friends and engaging in vigorous physical activities.

\section{CONCLUSION}

Students in college constantly undergo different stressors that stem from varying sources. They control and reduce stress with strategies such as social support, self-motivation, and religious activities. The researchers conclude that college student with good mental health have positive coping techniques in relieving stress.

\section{RECOMMENDATIONS}

Based on the result of the study, it is recommended to strengthen coordination among the guidance office, the Department of Student Affairs, the respective colleges and schools, faculty, staff, employees, students and all other stake holders in raising awareness, oneon-one counseling sessions, seminars and forums in order to foster a stress free environment and a helpful, empathetic academe. Moreover, for future researchers to embark on the same study regarding stress to include specific colleges/schools within the Institute in order to come up with a comparative analysis on the effect of stressors and its sources that vary in different specialized environments, courses or departments.

\section{REFERENCES}

American College Health Association (2015). National College Health Assessment II The ACHA-NCHA II supports the health of the campus community by fulfilling the academic mission, supporting shortand longterm healthy behaviors, and gaining a current profile of health trends within the campus community. Executive Summary University of California Davis Undergraduate, California. Retrieved from: https://shcs. ucdavis. edu/sites/default/files/documents/NCHA-II_SPRING_2015.pdf

Brougham, R.R., Zail, C.M., Celestal, M. \& Miller, J.R. (2009). Stress, sex differences, and coping strategies among college students. Current Psychology, 28(2), pp 85-97.

Chien, J. (2015). The relationship of perceived stress, religious coping styles, and mental health symptoms in university students. PhD. Florida Atlantic University, USA.

Dy, M., Espiritu-Santo, K., Ferido, M. \& Sanchez, R. (2015). Stressors and stress responses of Filipino college students. Asia life sciences, 24(2), pp 737-759.

Fishman, J.S. (2012). Psychological Resilience, Perceived Stress, and Stress Reaction. Walden University, Minnesota.

Gadzella, B.M., Baloglu, M., Masten, W.G. \& Wang, Q.M., (2012). Evaluation of the Student Life-stress Inventory-Revised. Journal of Instructional Psychology, 39(2), pp 82-91. 
Gupchup, G.V., Borrego, M.E. \& Konduri, N. (2004). The Impact of Student Life Stress on Health-Related Quality of Life Among Doctor of Pharmacy Students. College Student Journal [online], 38(2), pp 292-302.

Hamaideh, S. (2011). Stressors and Reactions to Stressors Among University Students. International Journal of Social Psychiatry, 57(1), pp 69-80.

Hicks, T. \& Heastie, S. (2008). High school to college transition: A profile of the stressors, physical and psychological health issues that affect the first-year on-campus college student. Journal of Cultural Diversity, 15(3), pp 143-147.

Kim, S., Kim, H. \& Yang, J. (2015). Psychological and Emotional Stress among the Students Living in Dormitory: A Comparison between Normal and Depressive Students. Journal of Sleep Disorders \& Therapy, 4(3).

Mathew, C.P. (2017). Stress and Coping Strategies among College Students. IOSR Journal of Humanities and Social Science, 22(8), pp 40-44.

Pariat, M., Rynjah, M., Joplin, M. and Kharjana, M. (2014). Stress Levels of College Students: Interrelationship between Stressors and Coping Strategies. IOSR Journal of Humanities and Social Science, 19(8), pp 40-45.

Ramya, N. \& Parthasarathy, R. (2009). A study on coping patterns of junior college students. Indian Journal of Psychological Medicine, 31(1), pp 45.

Silvers, S.A. (2006). Perceived social support, coping strategies, and depression during the transition to college. Northern Illinois University, Illinois.

Siraj, H.H., Salam, A., Roslan, R., Hasan, N.A., Jin, T.H. \& Othman, M.N. (2014). Stress and its association with the academic performance of undergraduate fourth year medical students at Universiti Kebangsaan Malaysia. The International Medical Journal Malaysia, 13(1), pp 19-24. 